\title{
Salonen, Kirsi.
}

\section{Papal Justice in the Late Middle Ages: The Sacra Romana Rota.}

Abingdon, UK: Routledge 2016. Pp. xv, 199. ISBN 978-1-4724-8226-6 (hardcover) \$149.95.

Kirsi Salonen's study of the papal tribunal called the Sacra Romana Rota offers an excellent model of compelling institutional history, and should be useful to scholars of premodern justice and the Catholic Church. However, it also reveals a great deal about how historians are actively grappling with the current emphasis on big data and revisionist history, and with the trend to publish frequent monographs. We should pay attention, in our field, to the products and ways of accommodating these pressures.

Much like Salonen's earlier work with Jussi Hanska and Ludwig Smugge, this monograph is thought-provoking and data-driven. The study's larger goal is to describe the activity and role of the often-ignored Rota and to evaluate conclusions drawn by earlier Rotal scholars. The first part of Salonen's book (chapters 1-7) examines the Rota's purpose, process, and personnel, in order to introduce readers to the tribunal's administrative culture and its archival offerings. Salonen explores the tribunal's origin, development, practices, and normative texts. These discussions are set against the descriptions offered by early modern litigants and modern historians, who painted the Rota as an expensive and inefficient organ that privileged curial appellants and implicitly encouraged simony, pluralism, and absenteeism. Salonen tests this characterization in the book's second part, and uses the larger explanation of the Rota's administrative practice to explore the difficulties inherent in all studies of its juridical activity.

A great part of scholars' avoidance of the Rota is due to the challenges of its archive, which is spread across smaller collections in the Vatican Secret Archive. The largest and most important archival series is the Manualia Actorum (1464-1800), in which the responsible notary recorded each case's procedural stage chronologically, and which forms the foundation of Salonen's study. The twelve auditors (judges) and the forty-eight notaries employed by the Rota handled hundreds of thousands of cases from the late Middle Ages to the eve of the Reformation, of which only a fraction survive. Sadly, there is little discussion of the career paths of these auditors and notaries, or the advocates and proctors who worked with them. In order to investigate the Rota's activities 
in a statistically significant fashion, Salonen collected a large yet manageable sample of four complete years $(1466,1486,1506$, and 1526) and the wellpreserved work of the long-lived auditor Johannes de Ceretanis (1471-92). Using this sample of more than 27,000 procedural entries concerning 5,439 cases, Salonen argues that a more representative picture of the Rota emerges than is seen in the work of earlier scholars who investigated much smaller slices of the archive.

This large data set is put to excellent use in the monograph's second part (chapters 8-11) in which Salonen asks and answers four questions through quantitative and qualitative analyses that get to the heart of Rotal practice and reputation. Chapter 8 investigates how many and what kinds of processes were brought before the auditors. The results reinforce previous scholarship, which argues that, overwhelmingly, benefice arbitration was the primary purpose in turning to the Rota, with cases of property dispute, marital issues, and wideranging "other issues" following far behind. In chapter 9, Salonen applies chronological and geographic lenses to these results to determine whether variations occur that reflect differing geographic distances and political or ecclesiastical situations. These results affirm definitively that the two chief factors affecting the provenance of litigation were the number of inhabitants in a territory and the proximity between the litigants' home territory and the papal curia. The cooling or inflaming of relationships also affected the number of cases that appeared before the Rota, as French cases reduced in light of the Pragmatic Sanction of Bourges (1438) and cases from Italian states increased after Pope Innocent VIII's decree expanding the Rota's juridical authority (1488).

In chapter 10, Salonen focuses on the length of the Rota's process in order to investigate the truth of accusations that the tribunal was ineffective due to corrupt inefficiency. Using a model that defines procedural efficiency and effectiveness as the timely progress of a case from commissio to sententiae, Salonen identifies ten stages as the minimum threshold. The results drawn from the 5,439 cases indicate that 74 percent of all cases resolved within six months and only 14 percent lasted for more than a year. This stands in stark contrast to the stereotype of multi-year litigation. Curiously, the results also revealed that 71 percent of cases did not progress to the minimum of ten stages, but died before a sentence was passed. Salonen proposes a connection between the rhetorical standard of "endless litigation" (156) and the widespread practice 
of initiating litigation in order to intimidate an adversary into settling out of court. Both practices suggest that litigants were willing to switch judges, delay progress, or force a settlement rather than proceed swiftly to a sentence. These possibilities appear likely in light of the large number of unresolved cases, but remain unproven hypotheses until further work progresses on the content and course of these cases. Finally, in an effort to begin that work, chapter 11 explores the litigants' identities and possible strategies in applying to the Rota. This investigation tests the accusation that the Rota best served litigants who were Rotal employees or affiliates and members of the papal court. The difficulty in reliably identifying litigants from the Manualia Actorum undercuts the strength of this chapter, but Salonen suggests that curialists appeared fairly often as litigants, based on their proximity and knowledge of the curia, while foreign benefice-hunters were deterred from applying.

While this study stands as an opportunity to revise incomplete arguments about the Rota's role in papal justice, and laudably to test preconceptions with larger data sets, it also reveals a great deal about big data history in the age of "publish or perish." Salonen's text is a strong and compelling contribution to the field of institutional history, which is built perceptibly on her own and other scholars' previous work. Yet its archival compromises and brief text, both reasonable and not unpleasant, contrast with the tomes of the mid-twentieth century that purportedly mastered an organization after two decades' work. Emerging from an archive of endless litigation, Salonen's book may prompt readers to wonder if necessary projects like this one are irreconcilably at variance with the current expectation of a five-year monograph production cycle.

JENNIFER MARA DESILVA

Ball State University 